\title{
HPV Pozitif Olan Hastaların HPV Hakkında Bilgileri ve HPV aşılarına Yaklaşımı: Tersiyer Bir Merkezin Deneyimi
}

\author{
HPV Positive Patients' Knowledge of HPV and Perspectives about HPV Vaccine: A Tertiary Center Experience
}

\author{
Yunus Emre PURUT ${ }^{1}$, Şeyma Nur PURUT ${ }^{2}$, Burak GIRAY ${ }^{3}$, Zeliha YAZICI ${ }^{2}$, Canan KABACA ${ }^{4}$ \\ 1. S.B.Ü. Van Eğitim ve Araştırma Hastanesi, Kadın Hastalıklarl ve Doğum Kliniği, Van, Türkiye \\ 2. Biruni Üniversitesi, Istanbul, Türkiye \\ 3. Sancaktepe Şehit Prof. Dr. İlhan Varank Eğitim ve Araştırma Hastanesi, İstanbul, Türkiye \\ 4. İstanbul Zeynep Kamil Jinekoloji ve Pediatri Sağlık Araştırma Merkezi,, İstanbul, Türkiye
}

\section{$\ddot{O Z Z E T}$}

Amaç: Tersiyer bir merkeze kolposkopik inceleme için refere edilen hastaların Human Papillomavirus (HPV) hakkındaki bilgilerini ve HPV aşısına yaklaşımını değerlendirmeyi amaçladık.

Gereçler ve Yöntem: 01.12.2018 ile 01.05.2019 tarihleri arasinda üçüncü basamak sağlık kuruluşunda kolposkopik inceleme yapılan 197 HPV pozitif hasta çalışmaya dahil edildi.

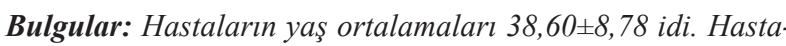
ların yaklassı \%56,9'unun HPV asısı hakkinda bilgisi olmasına rağmen, \%86,8'i her kadının aşı yaptırması gerektiğini düşünmüyordu. HPV aşısı yaptırmama sebebi olarak da hastaların $\%$ 40,6’sı hekimlerin aralarında bir fikir birliği olmadiğını söylemistir. HPV hakkinda önceden bilgi sahibi olan ile olmayan hastalar arasında eğitim durumu açısından istatiksel bir farklılık bulunmamıștır $(p=0,291)$. HPV hakkında önceden bilgisi olanların \%55,7 si düzenli smear yaptırdı̆̆ını bildirmiştir. HPV hakkında bilgisi olan hastalar ile olmayan hastalar arsinda düzenli smear taraması yaptırması açısından anlamlı fark vardı $(p=0,001)$.

Sonuç: Hastaların HPV hakkında bilgisi olduğu halde HPV aşısının güvenliği ve aşının koruması hakkında endişeye sahiptiler.

Anahtar Kelimeler: HPV aşısı, HPV, smear, ko-test

\section{ABSTRACT}

Objective: We aimed to examine knowledge of Human Papillomavirus (HPV) and perspectives about HPV vaccine of patients referred to a tertiary hospital for colposcopic examination.

Material and Methods: One hundred ninety-seven HPV positive patients undergoing colposcopic examination at a tertiary center between 01.12.2018 and 01.05.2019 were included to the study.

Results: The mean age of the patients was $38.60 \pm 8.78$ years. Although $56.9 \%$ of the patients had knowledge of HPV vaccine, $86.8 \%$ of the patients did not consider that every woman should be vaccinated. About $41 \%$ of the patients stated that there was no consensus among physicians as a reason why women did not have HPV vaccination. There was no statistically significant difference between patients with and without knowledge of HPV in terms of educational status ( $p=0.291)$.

\section{İletișim}

Sorumlu Yazar: Yunus Emre PURUT

Adres: S.B.Ü. Van Eğt. ve Arș. Hastanesi, Kadın Hast. ve Doğum Kliniği, Süphan Mh, Havayolu Kavşağı 1. Km, Edremit, Van, Türkiye Tel: +90 (505) 2300500

E-Posta: purutemreyunus@hotmail.com

Makale Geliș: 01.12.2020

Makale Kabul: 20.12 .2020

DOI: http://dx.doi.org/10.16948/zktipb.834608
About 56\% of the patients with knowledge of HPV stated that they had regular smear tests. There was a statistically significant difference between patients with and without knowledge of $H P V$ in terms of having regular smear tests $(p=0.001)$.

Conclusion: Although patients had knowledge of HPV, they had anxieties about vaccine safety and vaccination coverage.

Keywords: $H P V$ vaccine, $H P V$, smear, co-test

\section{GİRIŞ}

Serviks kanseri prevalansı dünya genelinde kadınlar arasında en yaygın görülen üçüncü kanserdir. Son yillarda servikal intraepitelyal neoplazi (CIN) insidansı iki kat artmış ve ortalama görülme yaşı azalmıştır. Aynı zamanda kırk yaşın altındaki kadınlarda servikal kanser insidansı da giderek artmaktadır. Servikal karsinomların insidans1 ve mortalite hızı, serviks kanseri tarama programlarından dolayı erken tanı ve tedavi ile etkin bir șekilde azalmaktadır [1]. Toplumun yaklaşık \%15'inin Human Papillomavirus (HPV) ile enfekte olduğu bilinmektedir. HPV bulașma oranının ise $\% 75$ olduğu saptanmıştır [2]. HPV DNA testinin 25 yaş altı olgularda \%32-64 oranında pozitif sonuç verdiği, 45 yaş ve üzerinde ise bu oranın \%2,8-4 olduğu saptanmıştır [3]. Serviks kanserinin sekonder önlenmesi tarama ile sağlanırken, primer önleme HPV aşısı ve sağlık eğitimi yoluyla mümkün olmaktadır. Başarılı bir HPV aşılama programının uzun vadeli etkilerinden biri serviks kanseri insidans1 ve mortalitesinin azaltılmasıdır. Biz bu araştırmada tersiyer bir merkeze kolposkopi için refere edilen hastaların HPV ve aş1 hakkındaki farkındalığını ve aşıya yaklaşımlarını değerlendirmeyi amaçladık.

\section{GEREÇ ve YÖNTEM}

Çalışmamıza 01.12.2018 ile 01.05.2019 tarihleri arasında, serviks kanseri taraması sonucu HPV testi pozitif olan ve Jinekolojik Onkoloji Polikliniği'ne kolposkopi yapılması amacıyla yönlendirilen 197 hasta dahil edilmiştir. Servikal erozyon, postkoital kanama, makroskobik şüpheli lezyon ya da smear bozukluğu gibi sebeplerle kolposkopiye yönlendirilen ancak HPV durumu bilinmeyen ya da negatif hastalar çalışma dışında bırakıldı. Hastalar seçilirken; sözel iletişim kurabilmesi, 18 yaş ve üzeri olması, okuryazar olması, görme ve işitme 
kaybının olmaması, HPV pozitifliği ile kolposkopi amacı ile gelmiş ve araştırmaya katılmayı kabul etmiş olması kriterleri göz önünde bulunduruldu. Araştırmanın verileri yüz yüze görüşme tekniği ile veri toplama formu kullanılarak araştırmacılar tarafindan toplandi. Hastaların demografik verilerini elde etmek için eğitim durumları, doğum yerleri (il, ilçe, kasaba veya köy), medeni durumları, cinsel aktif olma yaşları, varsa doğum sayıları, doğum şekli ve sigara kullanıp kullanmadıkları soruldu. Hastaların korunma yöntemleri ve smear takibi yaptırıp yaptırmadıkları bilgisi de elde edildi. Kanser korkusunu değerlendirmeleri için 0-hiç korkmuyorum, 10 ise çok korkuyorum şeklinde temsil edecek biçimde işaretlenmeleri istendi.

Hastaların HPV hakkındaki görüşlerini değerlendirmek için de daha önceden HPV taraması yaptırıp yaptırmadığı, önceden HPV hakkında bilgisinin olup olmadığı ve HPV'yi nereden duyduğu gibi sorular yöneltildi.

Tablo 1: Hastaların demografik verilerir.

\begin{tabular}{|c|c|c|c|}
\hline & & $\mathrm{n}$ & $\%$ \\
\hline & Okur-yazar değil & 6 & 3 \\
\hline & İlkokul & 47 & 23,9 \\
\hline Eğitim durumu & Ortaokul & 23 & 11,7 \\
\hline & Lise & 56 & 28,4 \\
\hline & Üniversite ve üzeri & 65 & 33 \\
\hline & İl & 123 & 62,4 \\
\hline & İlçe & 54 & 27,4 \\
\hline & Kasaba & 8 & 4,1 \\
\hline & Köy & 12 & 6,1 \\
\hline & Evli & 65 & 33 \\
\hline 178 & Evli değil & 132 & 67 \\
\hline & Belirtmek istemeyen & 20 & 10,2 \\
\hline & $15-20$ yaş & 76 & 38,6 \\
\hline Cinsel aktif & $21-25$ yaş & 10 & 5,1 \\
\hline olma yaşı & $26-30$ yaş & 24 & 12,2 \\
\hline & $31-35$ yaş & 6 & 3 \\
\hline & 35 ve üzeri & 2 & 1 \\
\hline & 0 & 45 & 22,8 \\
\hline & $1-2$ & 110 & 55,8 \\
\hline & $3-4$ & 35 & 17,8 \\
\hline & 4 ve üzeri & 7 & 3,6 \\
\hline & Yok & 45 & 22,8 \\
\hline & Vajinal doğum & 59 & 29,9 \\
\hline & Sezaryen doğum & 79 & 40,1 \\
\hline & Vajinal ve sezaryen doğum & 14 & 7,1 \\
\hline Sigara & Var & 115 & 58,3 \\
\hline kullanımı & Yok & 82 & 41,7 \\
\hline
\end{tabular}

HPV aşısı ve HPV aşısına yaklaşımlarını değerlendirmek için ise aşı hakkında bilgilerinin olup olmadığı, rahim ağzı kanseri ile ilişkisini bilip bilmedikleri, aşının koruyucu etkisi hakkında ne düşündükleri, kendileri ve varsa kızları dahil her kadının aşı yaptırıp yaptırmaması konusundaki düşünceleri ve HPV aşısı hakkındaki endişeleri soruldu.

Çalışma için etik kurul komitesinden onay alınmıştır (No: 2018/24-03).

Araştırmada elde edilen bulgular değerlendirilirken, verilerin kodlanması ve istatistiksel analizleri için SPSS (IBM)-Windows 23.0 programı kullanılmıştır. Sonuçlar \%95'lik güven aralığında, anlamlılık $\mathrm{p}<0,05$ düzeyinde değerlendirilmiştir.

\section{BULGULAR}

Hastaların yaş ortalamaları $38,60 \pm 8,78$ idi. Hastaların eğitim durumu, doğum yeri ve evlilik durumu ile ilgili bilgiler Tablo-1'de verilmiştir (Tablo 1).

Kronik hastalık varlığı değerlendirmesinde hastaların \%72,6'sında kronik hastalık olduğu, \%27,4'ünde ise kronik hastalık olmadığı saptanmıştır. Hastaların \%55,3'ünün ailesinde birinci derece akrabalarında kanser vakası olduğu, \%44,7'sinde ise olmadığ 1 bulunmuştur. Çalışmada hastaların $\% 58,5$ 'inin sigara kullandığ $1,41,5$ 'inin ise sigara kullanmadığı bulunmuştur. Sigara kullanım süresi değerlendirildiğinde ise en yüksek oran $\% 17,8$ ile $10-20$ y1l arası, en düşük oran ise $\% 3$ ile $0-1$ yıl aras1 olarak saptanmıştır. Hastaların korunma yöntemleri, smear takibi yaptırıp yaptırmadıkları ve kanser korkusu yaşayıp yaşamadıkları ile ilgili bilgileri Tablo-2' de verilmiştir (Tablo 2).

Tablo 2: Hastaların korunma yöntemleri, smear takibi yaptırıp yaptırmadıkları ve kanser korkusu değerlendirmeleri ile ilgili bilgiler.

\begin{tabular}{|c|c|c|c|}
\hline & & $\mathbf{n}$ & $\%$ \\
\hline \multirow{9}{*}{ Korunma yöntemi } & Kullanmiyor & 92 & 46,7 \\
\hline & Cevap vermek istemiyor & 8 & 4,2 \\
\hline & Kondom & 41 & 20,8 \\
\hline & Doğum kontrol ilacı & 11 & 5,6 \\
\hline & Rahim içi araç & 19 & 9,6 \\
\hline & Geleneksel yöntemler & 16 & 8,1 \\
\hline & Tüp ligasyonu & 3 & 1,5 \\
\hline & Diğer* & 3 & 1,5 \\
\hline & Birkaç yöntem birlikte & 4 & 2 \\
\hline \multirow{2}{*}{$\begin{array}{l}\text { Düzenli smear } \\
\text { taraması }\end{array}$} & Yaptırıyor & 96 & 48,7 \\
\hline & Yaptırmiyor & 101 & 51,3 \\
\hline \multirow{6}{*}{$\begin{array}{l}\text { Kanser korkusu } \\
\text { (0-10 puan arası } \\
\text { değerlendirme) }\end{array}$} & 0 & 12 & 6,1 \\
\hline & 2 & 9 & 4,6 \\
\hline & 4 & 21 & 10,7 \\
\hline & 6 & 32 & 16,2 \\
\hline & 8 & 42 & 21,3 \\
\hline & 10 & 81 & 41,1 \\
\hline
\end{tabular}

\footnotetext{
* spermisit, vazektomi.
} 
Hastaların HPV ile ilgili bilgi düzeyleri Tablo 3 'te verilmiştir (Tablo 3 ).

Tablo 3: Hastaların HPV ile ilgili bilgi düzeyleri.

\begin{tabular}{|c|c|c|c|}
\hline & & n & $\%$ \\
\hline \multirow{2}{*}{$\begin{array}{l}\text { Daha önce HPV taraması yaptır- } \\
\text { dınız mı? }\end{array}$} & Evet & 111 & 56,3 \\
\hline & Hayır & 86 & 43,7 \\
\hline \multirow{2}{*}{$\begin{array}{l}\text { HPV hakkında önceden bilgim } \\
\text { vardı }\end{array}$} & Evet & 140 & 71,1 \\
\hline & Hayır & 57 & 28,9 \\
\hline \multirow{2}{*}{$\begin{array}{l}\text { HPV pozitifliği sonrası HPV } \\
\text { hakkında bilgi edindim }\end{array}$} & Evet & 34 & 17,3 \\
\hline & Hayır & 163 & 82,7 \\
\hline \multirow{5}{*}{$\begin{array}{l}\text { HPV ile ilgili bilgi edinme } \\
\text { kaynağı }\end{array}$} & Hekim & 99 & 41,3 \\
\hline & Eczac1 & 22 & 9,1 \\
\hline & İnternet & 74 & 30,8 \\
\hline & Televizyon & 21 & 8,8 \\
\hline & Dergi/broşür & 24 & 10 \\
\hline
\end{tabular}

HPV aşısı ile ilgili bilgi düzeyleri ile HPV aş1sına yaklaşımları ise Tablo 4'te verilmiş̧tir (Tablo 4).

Tablo 4: Hastaların HPV aşısı ile ilgili bilgi düzeyleri ile HPV aşısına yaklaşımları.

\begin{tabular}{|c|c|c|c|}
\hline & & n & $\%$ \\
\hline \multirow{2}{*}{$\begin{array}{l}\text { HPV aşısı hakkında bilgim } \\
\text { var. }\end{array}$} & Evet & 112 & 56,9 \\
\hline & Hayır & 85 & 43,1 \\
\hline \multirow{2}{*}{$\begin{array}{l}\text { HPV'nin birçok alt tipi } \\
\text { olduğunu ve bunların bazı- } \\
\text { larının rahim ağzı kanseri } \\
\text { ile ilişkili tipler olduğunu } \\
\text { biliyorum. }\end{array}$} & Evet & 43 & 21,8 \\
\hline & Hayır & 154 & 78,2 \\
\hline \multirow{2}{*}{$\begin{array}{l}\text { Aşı yaptırırsam HPV tipleri } \\
\text { ile olabilecek enfeksiyon- } \\
\text { ları aşının önleyebileceğini } \\
\text { düşünüyorum. }\end{array}$} & Evet & 75 & 38,3 \\
\hline & Hayır & 122 & 61,7 \\
\hline \multirow{2}{*}{$\begin{array}{l}\text { HPV taraması yaptırmadan } \\
\text { önce aşının yüksek } \\
\text { koruyuculuğu hakkında } \\
\text { bilgim vardı. }\end{array}$} & Evet & 45 & 22,8 \\
\hline & Hayır & 152 & 77,2 \\
\hline \multirow{2}{*}{$\begin{array}{l}\text { HPV ve aşısı hakkında } \\
\text { yeterli bilgiye sahip } \\
\text { olduğumu düşünüyorum. }\end{array}$} & Evet & 53 & 26,9 \\
\hline & Hayır & 144 & 73,1 \\
\hline \multirow{2}{*}{$\begin{array}{l}\text { Sizce her kadın HPV aşısı } \\
\text { yaptırmalı mı? }\end{array}$} & Evet & 26 & 13,2 \\
\hline & Hayır & 171 & 86,8 \\
\hline \multirow{5}{*}{$\begin{array}{l}\text { HPV aşısı hakkında en } \\
\text { büyük endişem }\end{array}$} & $\begin{array}{l}\text { Aşının yan etkileri } \\
\text { olduğunu düşünü- } \\
\text { yorum }\end{array}$ & 46 & 21,2 \\
\hline & $\begin{array}{l}\text { Aşının etkili olmaya- } \\
\text { cağını düşünüyorum }\end{array}$ & 38 & 17,5 \\
\hline & $\begin{array}{l}\text { Aşının pahalı oldu- } \\
\text { ğunu düşünüyorum }\end{array}$ & 41 & 18,9 \\
\hline & $\begin{array}{l}\text { Aşının kanser yapa- } \\
\text { bileceğini düşünü- } \\
\text { yorum }\end{array}$ & 4 & 1,8 \\
\hline & $\begin{array}{l}\text { Aşı hakkında hekim- } \\
\text { ler arasında bir fikir } \\
\text { birliği olmadığını } \\
\text { düşünüyorum. }\end{array}$ & 88 & 40,6 \\
\hline \multirow{2}{*}{$\begin{array}{l}\text { HPV aşısı olmayı } \\
\text { düşünüyor musunuz? }\end{array}$} & Evet & 27 & 13,7 \\
\hline & Hayır & 170 & 86,3 \\
\hline \multirow{2}{*}{$\begin{array}{l}\text { Kızınız varsa/ileride olursa } \\
\text { HPV'ye karşı aşılatmayı } \\
\text { düşünür müsünüz? }\end{array}$} & Evet & 27 & 13,7 \\
\hline & Hayır & 170 & 86,3 \\
\hline
\end{tabular}

HPV, aşı ve HPV aşısına kişilerin bakış açısının, demografik veriler ile ilişkisi Tablo-5'te verilmiștir (Tablo 5). HPV aşısı hakkında bilgim var diyenlerin çoğunluğu (\%33) ilkokul mezunu olup, bilgisi olmayanların çoğunluğu $(\% 51,8)$ ise üniversite ve üzeri mezunudur. HPV aşısı hakkında bilgim var sorusu ile eğitim durumu arasında istatiksel anlamda farklılık bulunmuștur $(\mathrm{p}=0,000)$. Her kadın HPV aşısı yaptırmalı ile eğitim durumu arasında da yüksek oranda anlamlılık saptanmıştır $(\mathrm{p}=0,003)$ (Tablo 5).

Tablo 5: HPV aşısı hakkındaki bilgi düzeyi ve aşıya yaklaşımın eğitim durumu ile ilişkisi.

\begin{tabular}{|c|c|c|c|c|c|c|c|}
\hline & & \multicolumn{2}{|c|}{$\begin{array}{l}\text { HPV hakkın- } \\
\text { da önceden } \\
\text { bilgim vardı }\end{array}$} & \multicolumn{2}{|c|}{$\begin{array}{l}\text { HPV aşısı } \\
\text { hakkında } \\
\text { bilgim var }\end{array}$} & \multicolumn{2}{|c|}{$\begin{array}{l}\text { Her kadın } \\
\text { HPV aşısı } \\
\text { yaptırmalı }\end{array}$} \\
\hline & & Evet & Hayır & Evet & Hayır & Evet & Evet \\
\hline & & n (\%) & n $(\%)$ & n $(\%)$ & n (\%) & n (\%) & n (\%) \\
\hline \multirow{11}{*}{$\begin{array}{c}\text { Eğitim } \\
\text { duru- } \\
\text { mu }\end{array}$} & \multirow{2}{*}{$\begin{array}{l}\text { Okur } \\
\text { yazar } \\
\text { değil }\end{array}$} & 6 & 0 & 5 & 1 & 3 & 3 \\
\hline & & $(4,3)$ & & $(4,5)$ & $(1,2)$ & $(11,5)$ & $(1,8)$ \\
\hline & \multirow{2}{*}{ İlkokul } & 36 & 11 & 37 & 10 & 4 & 42 \\
\hline & & $(25,7)$ & $(19,3)$ & (33) & $(11,8)$ & $(15,4)$ & $(24,6)$ \\
\hline & \multirow{2}{*}{$\begin{array}{c}\text { Ortao- } \\
\text { kul }\end{array}$} & 15 & 8 & 15 & 8 & 3 & 20 \\
\hline & & $(10,7)$ & (14) & $(13,4)$ & $(9,4)$ & $(11,5)$ & $(11,7)$ \\
\hline & \multirow{2}{*}{ Lise } & 41 & 15 & 34 & 22 & 14 & 42 \\
\hline & & $(29,3)$ & $(26,3)$ & $(30,4)$ & $(25,9)$ & $(53,8)$ & $(24,6)$ \\
\hline & \multirow{2}{*}{$\begin{array}{c}\text { Üniv. ve } \\
\text { üzeri }\end{array}$} & 42 & 23 & 21 & 44 & 2 & 64 \\
\hline & & (30) & $(40,4)$ & $(18,8)$ & $(51,8)$ & $(7,7)$ & $(37,4)$ \\
\hline & $\mathrm{p}$ & 0,291 & & $0,000 *$ & & $0,003 *$ & \\
\hline \multirow{5}{*}{$\begin{array}{l}\text { Evli } \\
\text { misi- } \\
\text { niz? }\end{array}$} & \multirow{2}{*}{ Evet } & 46 & 19 & 30 & 35 & 5 & 60 \\
\hline & & $(32,9)$ & $(33,3)$ & $(26,8)$ & $(41,2)$ & $(19,2)$ & $(35,1)$ \\
\hline & Hayır & 38 & 38 & 82 & 82 & 21 & 111 \\
\hline & & $(67,1)$ & $(66,7)$ & $(73,2)$ & $(58,8)$ & $(80,8)$ & $(64,9)$ \\
\hline & $\mathrm{p}$ & 0,949 & & $0,033^{*}$ & & 0,209 & \\
\hline \multirow{5}{*}{$\begin{array}{c}\text { Sigara } \\
\text { kulla- } \\
\text { nımı }\end{array}$} & Evet & 89 & 26 & 67 & 48 & 16 & 99 \\
\hline & & $(63,6)$ & $(45,6)$ & $(59,8)$ & $(56,5)$ & $(61,5)$ & $(57,9)$ \\
\hline & Hayır & 51 & 31 & 45 & 37 & 10 & 72 \\
\hline & & $(36,4)$ & $(54,4)$ & $(40,2)$ & $(43,5)$ & $(38,5)$ & $(42,1)$ \\
\hline & $\mathrm{p}$ & $0,026 *$ & & 0,477 & & 0,092 & \\
\hline \multirow{5}{*}{$\begin{array}{c}\text { Ailede } \\
\text { kanser } \\
\text { hika- } \\
\text { yesi }\end{array}$} & Evet & 75 & 34 & 54 & 55 & 12 & 97 \\
\hline & & $(53,6)$ & $(59,6)$ & $(48,2)$ & $(64,7)$ & $(46,2)$ & $(56,7)$ \\
\hline & Hayır & 65 & 23 & 58 & 30 & 14 & 74 \\
\hline & & $(46,4)$ & $(40,4)$ & $(51,8)$ & $(35,3)$ & $(53,8)$ & $(43,3)$ \\
\hline & $\mathrm{p}$ & 0,437 & & $0,021 *$ & & 0,41 & \\
\hline \multirow{5}{*}{$\begin{array}{c}\text { Dü- } \\
\text { zenli } \\
\text { smear } \\
\text { tara- } \\
\text { masi } \\
\text { yaptır- } \\
\text { ma }\end{array}$} & Evet & 78 & 18 & 59 & 37 & 18 & 78 \\
\hline & & $(55,7)$ & $(31,6)$ & $(52,7)$ & $(43,5)$ & $(69,2)$ & $(45,6)$ \\
\hline & Hayır & 62 & 39 & 53 & 48 & 8 & 93 \\
\hline & & $(44,3)$ & $(68,4)$ & $(47,3)$ & $(56,5)$ & $(30,8)$ & $(54,4)$ \\
\hline & $\mathrm{p}$ & $0,001 *$ & & 0,19 & & 0,054 & \\
\hline
\end{tabular}

$* \mathrm{p}<0.05$. 


\section{TARTIŞMA}

Çalışmamızda hastaların genel olarak üniversite mezunu, ilde yaşayan ve evli olmadığ muştur. Hastaların yaş ortalamaları $38,60 \pm 8,78$ olarak bulunmuştur. Çalışmamızda sigara içme oranı \%58,3 bulunmuştur. Bu oran HPV ve sigara birlikteliği ile de uyumludur. HPV prevalansının araştırıldığı bir çalışmada, sigara kullanan kadınlarda HPV pozitif oran1 \%67,9 sigara kullanmayan kadınlarda $\% 27,3$ olarak bulunmuş ve istatistiksel olarak anlamlı olduğu saptanmıştır [4]. Çalışmada hastaların \%46,7'sinin hiçbir korunma yöntemi kullanmadığı, en çok kullanılan yöntemin ise prezervatif olduğu bulunmuştur. Görkem ve arkadaşlarının yaptığı çalışmada ise popülasyonun \%16,7'sinin hiçbir doğum kontrol yöntemi uygulamadığ $1, \% 6,3$ 'nün geri çekme yöntemi ile \%2,1'inin oral kontraseptif hap ile \%20,3'nün rahim içi araç ile \%20,3'nün kondom ile \%7,3'nün tubal ligasyon ile \%0,5'nin depo progesteron enjeksiyon ile korundukları bildirilmiştir [5]. Çalışmamız hastaların korunma yöntemi olarak tercih ettiği en popüler seçenek olan prezervatifin $(\% 20,8)$ HPV bulaşını literatürde vurgulandı ̆̆1 üzere azaltsa da yok etmediğine işaret eder. Yaptığımız çalışmada hastaların \%47,7'si düzenli smear yaptırdığını, \%51,3'ü ise yaptırmadığını belirtmiştir. Çalışmadaki hastalar kotest sonucu ile üst merkeze refere edilen hastalar olduğundan smear hakkında bilgi sahibi olup olmama konusunda çalışmamız toplumun genelini yansitamaz. Akça ve arkadaşlarının yaptı̆̆ çalışmada ise HPV'yi duyma sıklığ $1 \% 91,7$, HPV aşısını duyma sıklığ 1 \% 85,4'dür [6].

Çalışmamızda ise hastaların \%71,1'inin HPV ile ilgili önceden bilgisi olduğu saptadık. Ayrıca HPV pozitifliği sonrası HPV hakkında bilgi edinenlerin oran $1 \% 17,3$ olarak bulunmuştur. $\mathrm{Bu}$ oranda düşünülecek olursa HPV ile ilgili bilgi düzeyi Akça'nın çalışmasına yakın düzeyde tespit edilmiştir. Her iki çalışmada da HPV öğrenme kaynakları televizyon, dergi ve gazete olarak belirtilmiştir. Çalışmamıza HPV'si pozitif olan bireyler alındığından ya da başka bir bakış açısıyla çalışma genel popülasyon üzerine yapılmadığından HPV ile ilgili bilgisi olan hastaların oranı daha yüksek beklenirdi. Yine biz HPV ile ilgili bilgiyi hastaların \%41,3'nin hekimden, \%30,8'inin internetten edindiği saptadık. $\mathrm{Bu}$ durum hekime ulaşma konusunda günümüzdeki imkanların daha fazla olması ve internet kullanımının son dönemde ciddi artışı ile izah edilebilir. Bir çalışmada katılımcıların \%86,5'i HPV aşısı ile ilgili önceden bilgi sahibi olarak tespit edilmiştir [5]. Yaptığımız çalışmada HPV aşısı hakkında hastaların sadece \%56,9'unu bilgi sahibi olduğu, HPV'nin birçok alt tipi olduğunu ve bunların bazılarının rahim ağzı kanseri ile ilişkili tipler olduğunu bilenlerin oran 1 ise $\% 21,8$ olarak bulunmuştur. $\mathrm{Bu}$ durum HPV aşısının hala ulusal aşılama programımız kapsamında olmayışı ile ilgili olabilir. HPV taraması yaptırmadan önce aşının yüksek koruyuculuğu hakkında hastaların \%22,8'inin bilgisi olduğu ortaya konulmuştur. Hastaların sadece 53'ü $(\% 26,9)$ HPV aşısı ve HPV hakkında yeterli bilgiye sahip olduklarını düşünüyordu. HPV hakkında önceden bilgisi olan 140 hasta ve aşı hakkında fikir sahibi olan 112 hastaya rağmen sadece 53 hastanın yeterli düzeyde bilgi sahibi olduğuna inanıyor olması dikkat çekicidir. Aşı hakkında bilgi sahibi olduğunu belirten hastaların oranının \%56,9 olmasına rağmen, aşının yüksek koruyuculuğu olduğunu düşünen hastaların $\% 22,8$ olması da dikkat çekicidir. Hastaların büyük bir çoğunluğu $(\% 61,7)$ aşı yaptırmanın, aşının içerdiği HPV tipleri ile olabilecek enfeksiyonu önleyebileceğini düşünmüyordu. Hastalar daha yüksek oranda HPV aşısının koruyuculuğu konusunda yanlış seçeneği işaretlemiş ve hastaların HPV aşısı hakkında bilgi karmaşası içerisinde olduğu aşikardır. Bir çalışmada HPV aşısı hakkında bilgi eksikliği, aşıya güvenin tam olmayışı ve aşılamanın çoklu dozda olması da yaygınlaşmaya olumsuz katkı sağlamakta diye vurgulanmıştır [7]. Yine başka bir çalışmada HPV aşısının ücretli olma durumu aşılamanın yaygınlaşmasını engelleyen önemli nedenlerden biri olarak bildirilmiştir [8]. Çalışmada hastalara her kadın HPV aşısı yaptırmalı mı diye sorulduğunda $\% 86,8$ oranda hayır cevabı alınmıştır. Literatüre benzer olarak aşının yan etkilerinin olmas1 endişesi, aşının etkili olmadığı ve aşının pahalı olduğu düşüncesinin de aşı yaptırmama nedenleri arasında olduğu bulunmuştur [7]. Çalışmamızda genel olarak așı yaptırmama nedenleri arasında \% 40,6 oranında hekimler arasında bir fikir birliği olmadığı görüşü ilk sırada yer almıştır. Bu hekimler arasında aşı tartışmalarının hastaları fazlasıyla etkilediği fikrini verebileceği gibi, gerçekten aşı karşıtı bu kadar fazla hekim olup olmadığ 1 da bir araştırma konusu olabilir. İlter ve arkadaşları 2010 yılında yaptığı çalışmada Türk kadınlarının kızları için HPV aşısını kabul etme oranlarının yüksek olduğu bulmuştur [9]. Literatür çalışmasında katılımcı sağlık personelinin \% 74,5'inin kızları için HPV aşısını yaptırmayı tercih ettiği tespit edilmiştir [5]. Çalışmamızda ise literatüre ters olarak hastaların \%86,3'ünün kızlarını aşılatmayı düşünmedikleri görülmüştür. İncelenen çeşitli sosyodemografik değişkenler arasında yaş ve eğitim durumu farkındalık ile ilişkilendirilmiştir. Daha önce yapılan çok sayıda çalışma, eğitim düzeyleri ile HPV farkındalık puanları arasında güçlü ilişkiler olduğunu ortaya koymuştur $[10,11]$. Bizim çalıșmamızda HPV hakkında önceden bilgisi olan katılımciların $41(\% 29,3)$ 'i lise, $42(\% 30,0)$ 'si ise üniversite mezunudur. HPV hakkında önceden bilgisi olmayan katılımciların ise $15(\% 26,3)$ 'i lise ve $23(40,4)$ 'ü üniversite mezunudur. Eğitim durumu ve HPV hakkında önceden bilgi sahibi olunması arasında istatiksel bir farklılık bulunmamıştır $(p=0,291)$. Bu durum literatür ile uyuşmamaktadır. HPV aşısı hakkında bilgi varlığı ile medeni durum arasında anlamlılık vardır. Evli olmayan hastalar evlilere göre aşı hakkında daha fazla ve istatistiksel olarak anlamlı oranda bilgi sahibi olduklarını belirtmişlerdir. Başka bir çalışmada ise çalışmaya katılan evli olan hemşirelerin HPV enfeksiyonu ve HPV aşısı bilgi puan ortalamalarının bekar olanlara göre yüksek bulunmuştur [6]. Ayrıca ailede kanser varlığı ile HPV aşısı hakkında bilgi varlığı arasında da istatiksel anlamlılık bulunmuştur. Sigara kullanımı ve HPV hakkında önceden bilgi varlığ 1 arasında istatiksel farklılık bulunmuştur. Sigara kullanan 
kişiler veri toplama formlarımızda HPV hakkında daha çok bilgi sahibi olduklarını beyan etmişlerdir. HPV pozitifliği sonrası özellikle bu popülasyonda sigara bırakma oranları bir çalıșma konusu olabilir. Düzenli smear ve HPV hakkında önceden bilgi varlı̆g 1 arasında yüksek oranda ilişki bulunmuştur. $\mathrm{Bu}$ bağlantı günümüzde özellikle aile sağllğı ve toplum sağlı̆ı 1 merkezlerinde yapılan kotest sayesinde kuşkusuz ileride daha net ortaya çıkacaktır.

\section{SONUÇ}

Sonuç olarak, HPV testi pozitif olan hastaların eğitim düzeyine bakılmaksızın bu virüs hakkında bilgi sahibi oldukları ancak HPV aşısına karșı bir ön yarg1 olduğu düșünülmektedir. Çalıșmanın örnekleminin dar olması daha etkin ve kullanılabilir verilerin elde edilmesini etkilemiştir. Yapılacak olan çalışmaların toplumun tümünü yansıtan daha fazla sayıda hasta ile yapılması önerilmektedir.

\section{KAYNAKLAR}

1. Aydoğan S, Yazgan A, Taş EE, Gözalan A, Yavuz AF, Açıkgöz ZC. The presence and distribution of high-risk HPV types in simultaneous cervical cytology samples. Turk Hij Den Biyol Derg. 2018;75(1):13-20.

2. Koutsky, L. Epidemiology of genital human papillomavirus infection. Am J Med.

1997; 102(5):3-8

3. Burk RD, Kelly P, Feldman J, et al. Declining prevalence of cervicovaginal human papillomavirus infection with age is independent of other risk factors. Sex Transm Dis. 1996;23(4):333-41.

4. Esposito S, Bosis $S$, Pelucchi C, et al. Pediatrician knowledge and attitudes regarding human papillomavirus disease and its prevention. Vaccine. 2007;25(35):6437-6446.

5. Görkem Ü, Toğrul C, Inal HA, Salman-Özgü B, Güngör T. Üniversite hastanesinde çalıșan yardımcı sağlık personelinin Human Papilloma Virüs ve aşlsı hakkında bilgi düzeyleri ve tutumlarl. Turk Hij Den Biyol Derg. 2015;72(4):303-310.

6. Akça S, Selen F, Büyükgönenç L. Hemșirelerin Human Papilloma Virüs (HPV)

Enfeksiyonu ve HPV Așlsı Hakkındaki Bilgi Düzeyleri: Ĕgitim ve Araştırma Hastanesi

Örneği. Hemșirelikte Eğitim ve Araștırma. 2016;13(2),116-

121.

7. Leddy MA, Anderson BL, Gall S, Schulkin J. Obstetrician-gynecologists and the HPV vaccine: practice patterns, beliefs, and knowledge. J Pediatr Adolesc Gynecol. 2009;22(4):239-246.

8. Dursun P, Altuntas B, Kuscu E, Ayhan A. Women's knowledge about human papillomavirus and their acceptance of $H P V$ vaccine. Aust $N$ Z J Obstet Gynaecol.

2009:49(2):202-206

9. Ilter E, Celik A, Haliloglu B, et al. Women's knowledge of Pap smear test and human papillomavirus: acceptance of HPV vaccination to themselves and their daughters in an Islamic society. Int J Gynecol Cancer. 2010;20(6):1058-1062.
10. Ozan H. Kadın hastalıkları ve doğum polikliniğine başvuran hastaların human papillomavirüs ve HPV aşısı hakkındaki bilgi düzeylerinin belirlenmesi. Uludağ Üniversitesi Tip Fakültesi Dergisi. 2011;37(3):145-148.

11. Marlow LAV, Waller J, Wardle J. Public awareness that $H P V$ is a risk factor for cervical cancer. $\mathrm{Br} J$ Cancer. 2007;97(5):691. 